\title{
Annual cycle of ozone at and above the tropical tropopause: observations versus simulations with the Chemical Lagrangian Model of the Stratosphere (CLaMS)
}

\author{
P. Konopka ${ }^{1}$, J.-U. Grooß ${ }^{1}$, G. Günther ${ }^{1}$, F. Ploeger ${ }^{1}$, R. Pommrich ${ }^{1}$, R. Müller ${ }^{1}$, and N. Livesey ${ }^{2}$ \\ ${ }^{1}$ Forschungszentrum Jülich (ICG-1: Stratosphere), Jülich, Germany \\ ${ }^{2}$ Jet Propulsion Laboratory, California Institute of Technology, Pasadena, CA, USA
}

Received: 10 July 2009 - Published in Atmos. Chem. Phys. Discuss.: 1 September 2009

Revised: 9 December 2009 - Accepted: 14 December 2009 - Published: 11 January 2010

\begin{abstract}
Multi-annual simulations with the Chemical Lagrangian Model of the Stratosphere (CLaMS) were conducted to study the seasonality of $\mathrm{O}_{3}$ within the stratospheric part of the tropical tropopause layer (TTL), i.e. above $\theta=360 \mathrm{~K}$ potential temperature level. In agreement with satellite (HALOE) and in-situ observations (SHADOZ), CLaMS simulations show a pronounced annual cycle in $\mathrm{O}_{3}$, at and above $\theta=380 \mathrm{~K}$, with the highest mixing ratios in the late boreal summer. Within the model, this cycle is driven by the seasonality of both upwelling and in-mixing. The latter process occurs through enhanced horizontal transport from the extratropics into the TTL that is mainly driven by the meridional, isentropic winds. The strongest in-mixing occurs during the late boreal summer from the Northern Hemisphere in the potential temperature range between 370 and $420 \mathrm{~K}$. Complementary, the strongest upwelling occurs in winter reducing $\mathrm{O}_{3}$ to the lowest values in early spring. Both CLaMS simulations and Aura MLS $\mathrm{O}_{3}$ observations consistently show that enhanced in-mixing in summer is mainly driven by the Asian monsoon anticyclone.
\end{abstract}

\section{Introduction}

A quantitative understanding of transport across the tropical tropopause layer (TTL) which acts as a "gateway to the stratosphere" plays a key role in determining the stratospheric concentrations of water vapor and other chemical species (Fueglistaler et al., 2009a). The TTL, which roughly

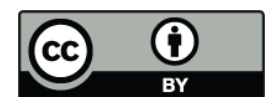

Correspondence to: P. Konopka (p.konopka@fz-juelich.de) extends vertically between 350 and $420 \mathrm{~K}$, is laterally confined by the subtropical jets, which vary seasonally both in their intensity and meridional position (e.g. Haynes and Shuckburgh, 2000; Konopka et al., 2007).

A direct consequence of transport is the composition of air within the TTL that shows a strong seasonality. In particular, at the tropical tropopause (i.e. $p \approx 100 \mathrm{hPa}$ or $\theta \approx 380 \mathrm{~K}, p$ pressure, $\theta$-potential temperature), high water vapor $\left(\mathrm{H}_{2} \mathrm{O}\right)$, high ozone $\left(\mathrm{O}_{3}\right)$, low carbon monoxide $(\mathrm{CO})$ during summer (seasons relative to the Northern Hemisphere) alternate with low $\mathrm{H}_{2} \mathrm{O}$, low $\mathrm{O}_{3}$ and high $\mathrm{CO}$ during winter (Folkins et al., 2006; Schoeberl et al., 2006; Randel et al., 2007).

In our work, we focus on the seasonality of $\mathrm{O}_{3}$ in the TTL with its pronounced summer maximum (Randel et al., 2007; Konopka et al., 2009). We discuss the question of how the horizontal transport from the extra-tropics into the stratospheric part of the TTL across its lateral boundaries (in the following we denote this kind of transport as in-mixing), modulates the vertical upward transport in the tropics, the socalled upwelling (see Fig. 1). More precisely, we understand in-mixing as the nearly isentropic net transport of air masses from the extratropics into the TTL. We show in this paper that this transport is mainly driven by meridional advection that reveals a strong seasonality with a much stronger transport from the Northern Summer Hemisphere in agreement with some previous purely diagnostic studies (Chen, 1995; Haynes and Shuckburgh, 2000; Ploeger et al., 2009).

The seasonality of $\mathrm{O}_{3}$ is shown as an example in Fig. 2 where the observations of the Southern Hemisphere ADditional OZonesondes (SHADOZ) network (Thompson et al., 2007) are used to determine the fractional annual cycle of $\mathrm{O}_{3}$ in the tropics, $\Delta \mathrm{O}_{3} /\left\langle\mathrm{O}_{3}\right\rangle$, (where $\left\langle\mathrm{O}_{3}\right\rangle$ is the annual mean, $\left.\Delta \mathrm{O}_{3}=\mathrm{O}_{3}-\left\langle\mathrm{O}_{3}\right\rangle\right)$. In the derivation of the seasonal

Published by Copernicus Publications on behalf of the European Geosciences Union. 


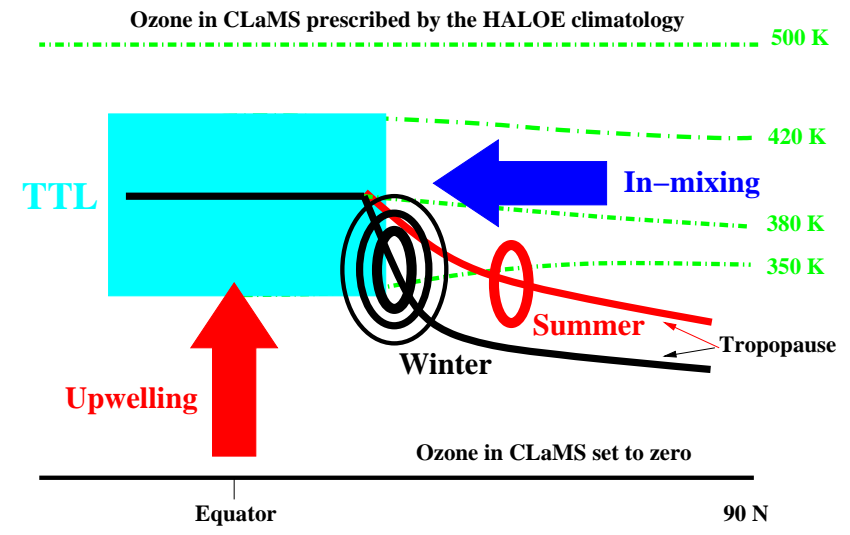

Fig. 1. Upwelling versus in-mixing. The seasonality of $\mathrm{O}_{3}$ within the TTL is determined mainly by the semi-annual cycle of photochemical production (as the Sun crosses the equator twice per year) and the annual cycle of transport with the strongest and weakest upwelling in boreal winter and summer, respectively. In this paper it is discussed how the annual cycle of upwelling interacts with the annual cycle of in-mixing, i.e. with the horizontal transport of midlatitude air masses into the TTL with the strongest contribution from the Northern Summer Hemisphere.

cycle of $\mathrm{O}_{3}$ we follow the procedure described in Randel et al. (2007) where ozone and temperature observations of the seven SHADOZ station closest to the equator (see subpanel in Fig. 2 for their geographical position) are considered, but instead of pressure we use potential temperature as the vertical coordinate. In particular, $p$-related observations of each station are transformed to $\theta$-levels using the measured temperatures and then averaged over all seven stations for each $\theta-$ level.

A clear annual cycle of $\Delta \mathrm{O}_{3} /\left\langle\mathrm{O}_{3}\right\rangle$, with the highest values of $\Delta \mathrm{O}_{3} /\left\langle\mathrm{O}_{3}\right\rangle$ in late summer and early fall in the $\theta$ range between 370 and $430 \mathrm{~K}$, can be diagnosed from the SHADOZ data. The lowest values appear approximately 4 5 months earlier. The pattern of this very pronounced cycle is similar to the analysis on the $p$-levels (Chae and Sherwood, 2007; Randel et al., 2007), although $\Delta \mathrm{O}_{3} /\left\langle\mathrm{O}_{3}\right\rangle$ is significantly smaller with peak anomaly 0.5 versus 0.3 during summer by using $p$ and $\theta$ as the vertical coordinate, respectively (Fueglistaler et al., 2009a; Konopka et al., 2009). As discussed by Konopka et al. (2009), a significant part of the variability of $\Delta \mathrm{O}_{3} /\left\langle\mathrm{O}_{3}\right\rangle$ on the $p$-levels is a seasonal adiabatic process (as the $p$-levels move relative to the $\theta$-levels during the year because of the seasonal cycle in temperature) that can be removed by using potential temperature $\theta$ as the vertical coordinate.

The seasonality of $\mathrm{O}_{3}$ above the level of zero clear sky radiation $(Q=0$ level around $\theta \approx 360 \mathrm{~K}$ as discussed in Gettelman et al., 2004) was recently explained as a consequence of the annual cycle in the tropical upwelling with the strongest and weakest upwelling in winter and summer, respectively (Randel et al., 2007). Randel et al. (2007) showed that the

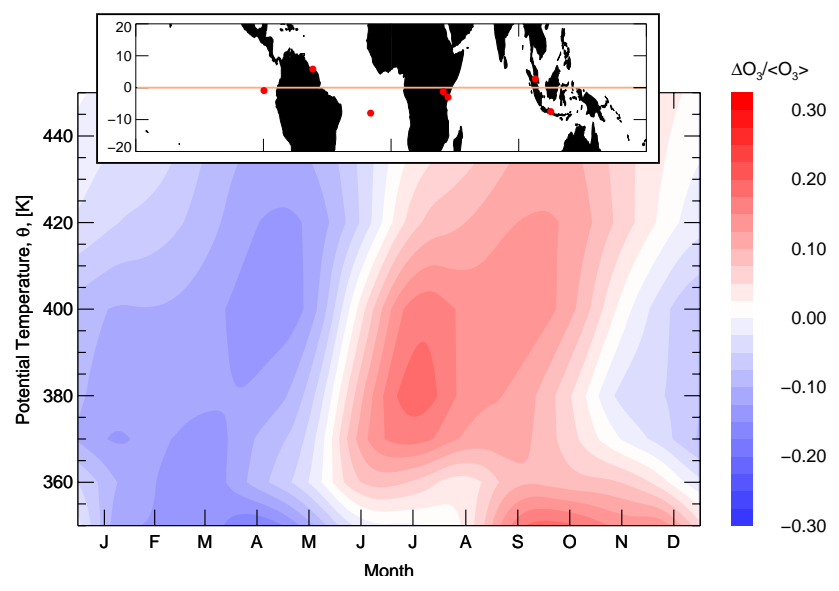

Fig. 2. The fractional annual cycle of $\mathrm{O}_{3}$ in the tropics, $\Delta \mathrm{O}_{3} /\left\langle\mathrm{O}_{3}\right\rangle$, ( $\left\langle\mathrm{O}_{3}\right\rangle$ - annual mean, $\left.\Delta \mathrm{O}_{3}=\mathrm{O}_{3}-\left\langle\mathrm{O}_{3}\right\rangle\right)$ averaged over the seven SHADOZ stations (red filled circles in the top sub-panel) closest to the equator (Thompson et al., 2007; Randel et al., 2007).

annual cycle of upwelling is approximately in phase with the well-known seasonal variation of the tropical temperatures with the highest (lowest) temperatures during the summer (winter). In particular, they assumed the tropics to be wellisolated from the extra-tropics, i.e. that in-mixing from the extratropics into the TTL is negligible. Recently, Schoeberl et al. (2008) followed the same arguments in order to explain the fluctuations in tropical trace gases observed by HALOE and Aura MLS instruments within the TTL.

However, as shown by our previous study based on the HALOE and SHADOZ observations of $\mathrm{O}_{3}$ and on a simple conceptual model of transport and photochemistry (Konopka et al., 2009), the observed seasonality of $\mathrm{O}_{3}$ on $\theta$-levels, with the highest values during boreal summer, cannot be understood solely by photolytical $\mathrm{O}_{3}$ production in slowly rising air masses which are well-isolated from the extratropics. By quantifying the photochemical production of $\mathrm{O}_{3}$ in ascending air and by using the SHADOZ climatology to estimate the tropospheric $\mathrm{O}_{3}$ mixing ratio, Konopka et al. (2009) determined the residual variability in observed $\mathrm{O}_{3}$ and interpreted this residuum as being caused by in-mixing.

Evidence of in-mixing into the TTL is not new (e.g. Volk et al., 1996; Avallone and Prather, 1997; Folkins et al., 1999). Using ozone sondes and aircraft observations of $\mathrm{N}_{2} \mathrm{O} / \mathrm{O}_{3}$ correlations, signatures of stratospheric contributions were found within the TTL above $14 \mathrm{~km}$ and well below the tropopause, thus identifying this region as a transition zone separating the troposphere from the stratosphere (Tuck et al., 1997). Recently, Marcy et al. (2007) showed that more than $60 \%$ of their airborne in situ $\mathrm{HCl}$ observations within the TTL (up to $\approx 100$ pptv below $\theta \approx 390 \mathrm{~K}$ ) are of stratospheric origin and that this $\mathrm{HCl}$ is well-correlated with $\mathrm{O}_{3}$.

Using the Chemical Lagrangian Model of the Stratosphere (CLaMS) (McKenna et al., 2002; Konopka et al., 2007), we 
discuss here how well the annual cycle of $\mathrm{O}_{3}$ above the tropical tropopause derived from satellite (HALOE) and in situ observations (SHADOZ) can be reproduced by this model. Whereas most of the published model studies on this topic are based on conceptual 2D-models, where the meridional transport is mostly neglected (see e.g. Read et al., 2008, and the citations therein), we show within a full 3-D study that inmixing significantly influences the composition of the lower tropical stratosphere, in particular the mixing ratios of $\mathrm{O}_{3}$ in summer. We also show that the summer Asian monsoon anticyclone drives such horizontal transport of sub- and extratropical air masses into the stratospheric part of the TTL.

\section{Configuration of CLaMS}

Multi-annual, global CLaMS simulations of the whole troposphere and stratosphere (from the ground up to $\theta=2500 \mathrm{~K}$ ) follow the model set-up described by Konopka et al. (2007) and cover the time period from October 2001 to December 2005 with $100 \mathrm{~km}$ horizontal resolution and the highest vertical resolution of $400 \mathrm{~m}$ around $\theta=380 \mathrm{~K}$. The horizontal winds are driven by the operational analysis of the European Centre for Medium-Range Weather Forecasts (ECMWF).

Above $100 \mathrm{hPa}$, the potential temperature $\theta$ is employed as the vertical coordinate of the model and the cross-isentropic velocity $\dot{\theta}$ is derived from a radiation calculation using the Morcrette scheme under clear sky conditions (Morcrette, 1991). Below $100 \mathrm{hPa}$, the model smoothly transforms from $\theta$ to a hybrid pressure-potential temperature coordinate $\zeta$ (i.e. below $\approx 300 \mathrm{hPa}$ and above $100 \mathrm{hPa}$, the $\zeta$ surfaces are parallel to $p$ - and $\theta$-surfaces, respectively) and, consequently, gradually includes the large-scale vertical velocity $\dot{p}$ from ECMWF (Mahowald et al., 2002).

In particular, the concept of the hybrid vertical velocity discussed in Konopka et al. (2007) mixes below $p=100 \mathrm{hPa}$ the ECMWF vertical velocity $\dot{p}$ with $\dot{\theta}$ derived from the clear-sky radiation calculation. In this approach, the radiation-related contribution of clouds and the contribution of latent heat to $\dot{\theta}$ could not be taken into account (because these terms are not archived by ECMWF). This approximation causes a gap in the annual mean tropical upwelling between $\theta=350$ and $360 \mathrm{~K}$ with negative vertical velocity in this part of the atmosphere. Ploeger et al. (2009) have recently shown that using the ERA-Interim re-analysis where, in contrast to the ECMWF operational analysis discussed here, these terms are available, the gap in tropical upwelling can indeed be closed.

However, this so-called diabatic approach, where the vertical velocity is derived from a diabatic heat budget, violates the continuity equation guaranteeing a mass-conserving transport. Here, in this paper, we correct the vertical velocity by using the condition that the zonally and annually averaged total mass fluxes should vanish at each $\theta$-level (Rosenlof, 1995) (see Appendix). In this way, we obtain mass-conserving transport on an annual scale. Moreover, the correction removes the unrealistic, negative values of the vertical velocity between $\theta=350$ and $360 \mathrm{~K}$. It is worthwhile to note that the vertical velocity in this part of the atmosphere is in any case very small (if not the smallest) and are a subject of current scientific debate (Krüger et al., 2009; Ploeger et al., 2009).

To illustrate how this procedure works, we show in the left panel of Fig. $3 \dot{\theta}=\dot{\theta}(d \theta / d \zeta)$ averaged over the 2002-2005 period for the corrected vertical velocity (i.e. following the procedure suggested by Rosenlof (1995), see Appendix) and compare in the right panel this corrected case with the vertical velocity discussed in Konopka et al. (2007) (reference case). In the left panel, the zonal and latitudinal $\left( \pm 10^{\circ} \mathrm{N}\right)$ average of $\dot{\theta}$ (corrected case) is plotted as a function of $\theta$ and season whereas the annual mean is shown in the right panel (black and red line for $\dot{\theta}$ in $\mathrm{K} / \mathrm{d}$ and $\mathrm{mm} / \mathrm{s}$, dash-dotted and solid line for the reference and the corrected case, respectively). The velocity $w$ in $\mathrm{mm} / \mathrm{s}$ was inferred from $\dot{\theta}$ in $\mathrm{K} / \mathrm{d}$ using $w=\dot{\theta} \cdot d z / d \theta$ with $d z / d \theta$ from the tropical climatology (Randel et al., 2007).

Thus, the part of the TTL around $\theta=360 \mathrm{~K}$, with a minimum in $\dot{\theta}$, couples the convection-dominated troposphere (semi-annual cycle of $\dot{\theta}$ ) with the radiation-dominated stratosphere (annual cycle of $\dot{\theta}$ ). Note that the annual cycle of tropical upwelling is a consequence of the hemispheric asymmetry of the land-sea distribution and of the orography which lead to hemispheric differences in the distribution and intensity of the wave drag driving the Brewer-Dobson circulation. In particular, the lowest tropical temperatures in winter correspond to the strongest wave drag in the Northern Hemisphere. On the other hand, the semi-annual cycle of convection is a consequence of a simple fact that the Intertropical Convergence Zone (ITCZ) roughly follows the Sun which crosses the equator twice per year.

Compared to the vertical velocity used in Konopka et al. (2007), the corrected vertical velocity enhances the mean tropical upwelling below the tropopause and removes the gap of the negative velocities around $\theta=350 \mathrm{~K}$ (the upper and lower edges of this gap are denoted in the left panel of Fig. 3 by two thick, dash-dotted white lines). Furthermore, the corrected vertical velocity also slightly decreases the upwelling above $\theta=380 \mathrm{~K}$ towards values which agree fairly well with the upwelling estimated from the upward propagation of the tape-recorder signals (Mote et al., 1998; Niwano et al., 2003) that is expected to be of the order of $0.3 \mathrm{~mm} / \mathrm{s}$ at $\theta=450 \mathrm{~K}$ (thick green dashed vertical line in the right panel of Fig. 3). In the following, we use the corrected vertical velocity as a default configuration and discuss the sensitivity of our results on the vertical velocity by using the reference configuration described in Konopka et al. (2007). 

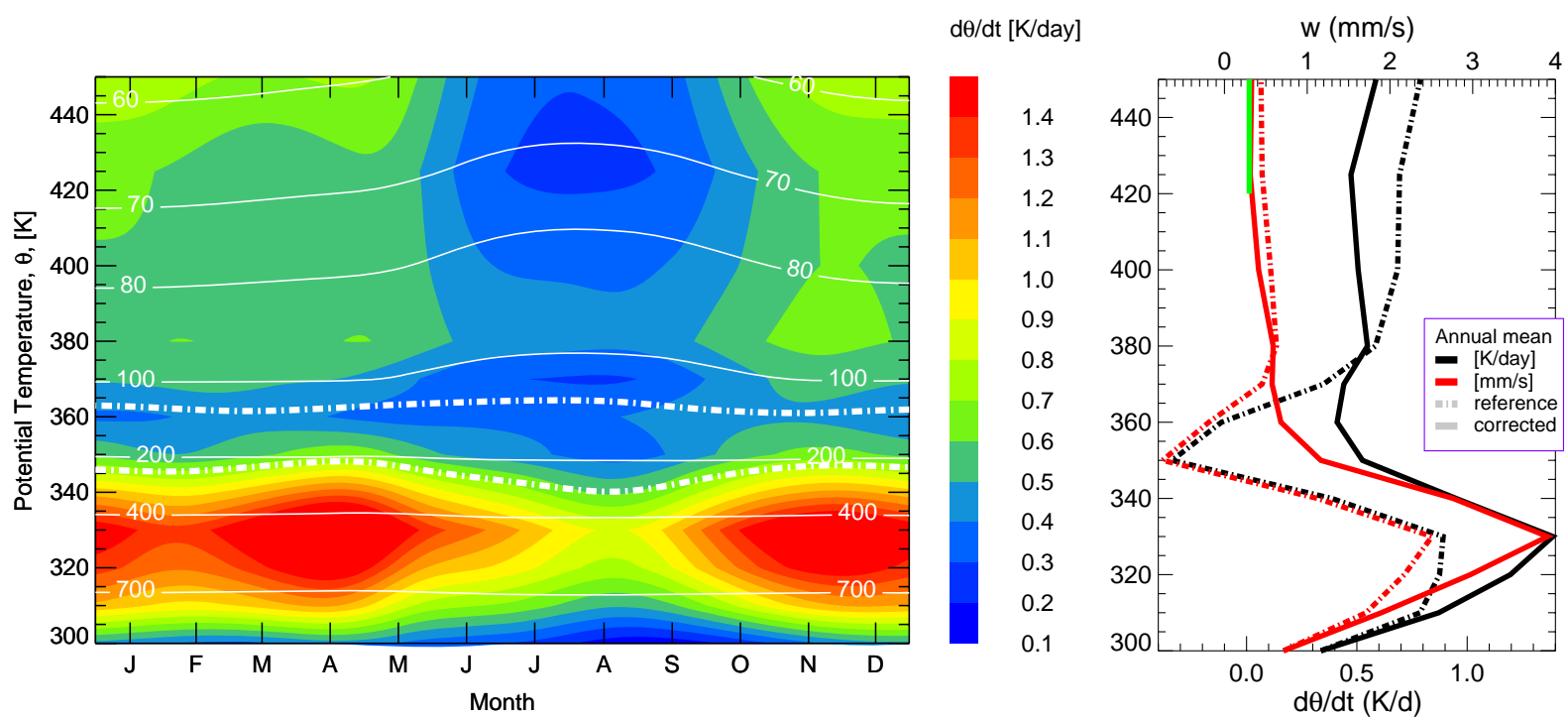

Fig. 3. Left: Seasonality of the upwelling in CLaMS described in term of $\dot{\theta}$ averaged zonally and within the $\pm 10^{\circ} \mathrm{N}$ range during the 2002-05 period (corrected case). White thin lines are isobars. The thick dash-dotted lines are $\dot{\theta}=0$ isolines of the reference case described in Konopka et al. (2007) (i.e. between these lines the vertical velocity is negative). Right: The corresponding annual mean of $\dot{\theta}$ for the corrected case (solid) compared with the reference case (dash-dotted). Black and red lines denote $\dot{\theta}$ in $\mathrm{K} / \mathrm{d}$ and mm/s, respectively. The green vertical line approximates the upwelling at $\theta=450 \mathrm{~K}$ with $w \approx 0.3 \mathrm{~mm} / \mathrm{s}$ derived from the upward propagation of the tape-recorder signal (Mote et al., 1998; Niwano et al., 2003).

\section{CLaMS simulations versus observations}

To study the seasonality of $\mathrm{O}_{3}$, CLaMS simulations with and without chemistry, i.e. for $\mathrm{O}_{3}$ and $\mathrm{P}-\mathrm{O}_{3}$ (passively transported $\mathrm{O}_{3}$ ), are now considered. For the chemistry of $\mathrm{O}_{3}$, only photolytical ozone production and the $\mathrm{HO}_{\mathrm{x}}$-driven $\mathrm{O}_{3}$ loss cycle in the lower stratosphere are taken into account. The $\mathrm{OH}$ concentrations are prescribed from a 2-D climatology (Grooß, 1996). Passively transported ozone $\left(\mathrm{P}-\mathrm{O}_{3}\right)$ allows the contribution of transport to be estimated, in particular that of in-mixing. $\mathrm{O}_{3}$ and $\mathrm{P}_{-} \mathrm{O}_{3}$ within the boundary layer (the lowest model layer) are set to zero. Because of this simplified chemistry all air parcels above $\theta=500 \mathrm{~K}$ are prescribed from the HALOE climatology (Grooß and Russell, 2005). In this way $\mathrm{O}_{3}$ and $\mathrm{P}_{-} \mathrm{O}_{3}$ are only calculated between the Earth's surface (both set to zero) and $\theta=500 \mathrm{~K}$ (both set to HALOE climatology, see also Fig. 1).

In Fig. 4, the seasonality of $\mathrm{O}_{3}$ (top) and $\mathrm{P}_{-} \mathrm{O}_{3}$ (middle) at $\theta=380 \mathrm{~K}$ derived from CLaMS is compared with the 10-year climatology of the Halogen Occultation Experiment (HALOE, bottom) (Grooß and Russell, 2005). Some differences between the CLaMS results and HALOE are obvious, in particular in the Southern Hemisphere where the contribution of the ozone hole is not reproduced in CLaMS (no halogen-induced chemistry in this version of CLaMS). However, a remarkable similarity in the annual pattern of the tropical $\mathrm{O}_{3}$ can be diagnosed for both data sets, in particular the maximum of HALOE $\mathrm{O}_{3}$ between July and November around the equator is reproduced fairly well by CLaMS $\mathrm{O}_{3}$ although the absolute values are overestimated.

Furthermore, the same seasonality as in $\mathrm{CLaMS} \mathrm{O}_{3}$ can also be diagnosed in $\mathrm{P}_{-} \mathrm{O}_{3}$, i.e. in passively transported $\mathrm{O}_{3}$ where any effect of chemistry is excluded. Because $\mathrm{P}-\mathrm{O}_{3}$ is set to 0 at the Earth's surface (in the same way as $\mathrm{O}_{3}$ ), the enhanced values of $\mathrm{P}_{-} \mathrm{O}_{3}$ can only originate from the stratosphere. In addition, the tropical values of $\mathrm{P}_{-} \mathrm{O}_{3}$ at $\theta=380 \mathrm{~K}$ level are of the same order as the values of $\mathrm{O}_{3}$ indicating that transport rather than chemistry drives the seasonality of $\mathrm{O}_{3}$ at the tropical tropopause.

To compare CLaMS results more quantitatively with observations, we plot in Fig. 5, the seasonality of $\mathrm{O}_{3}$ on $\theta=380$ and $420 \mathrm{~K}$. Here, SHADOZ observations are shown (beige) and CLaMS results are determined at the geographical locations of the seven SHADOZ stations considered (red and black for $\mathrm{O}_{3}$ and $\mathrm{P}-\mathrm{O}_{3}$, respectively). The gray line denotes the seasonality of $\mathrm{O}_{3}$ obtained from the HALOE climatology (Grooß and Russell, 2005) averaged within the latitude range $\pm 10^{\circ} \mathrm{N}$. The vertical lines around the SHADOZ data show the total variability between the seven stations considered. The difference between the HALOE and SHADOZ climatology probably results from the fact that the HALOE observations cover the $\pm 10^{\circ} \mathrm{N}$ latitude range almost uniformly whereas the SHADOZ climatology is biased by the geographical positions of the seven stations considered, of which five are located in the Southern Hemisphere (see also Konopka et al., 2009). 

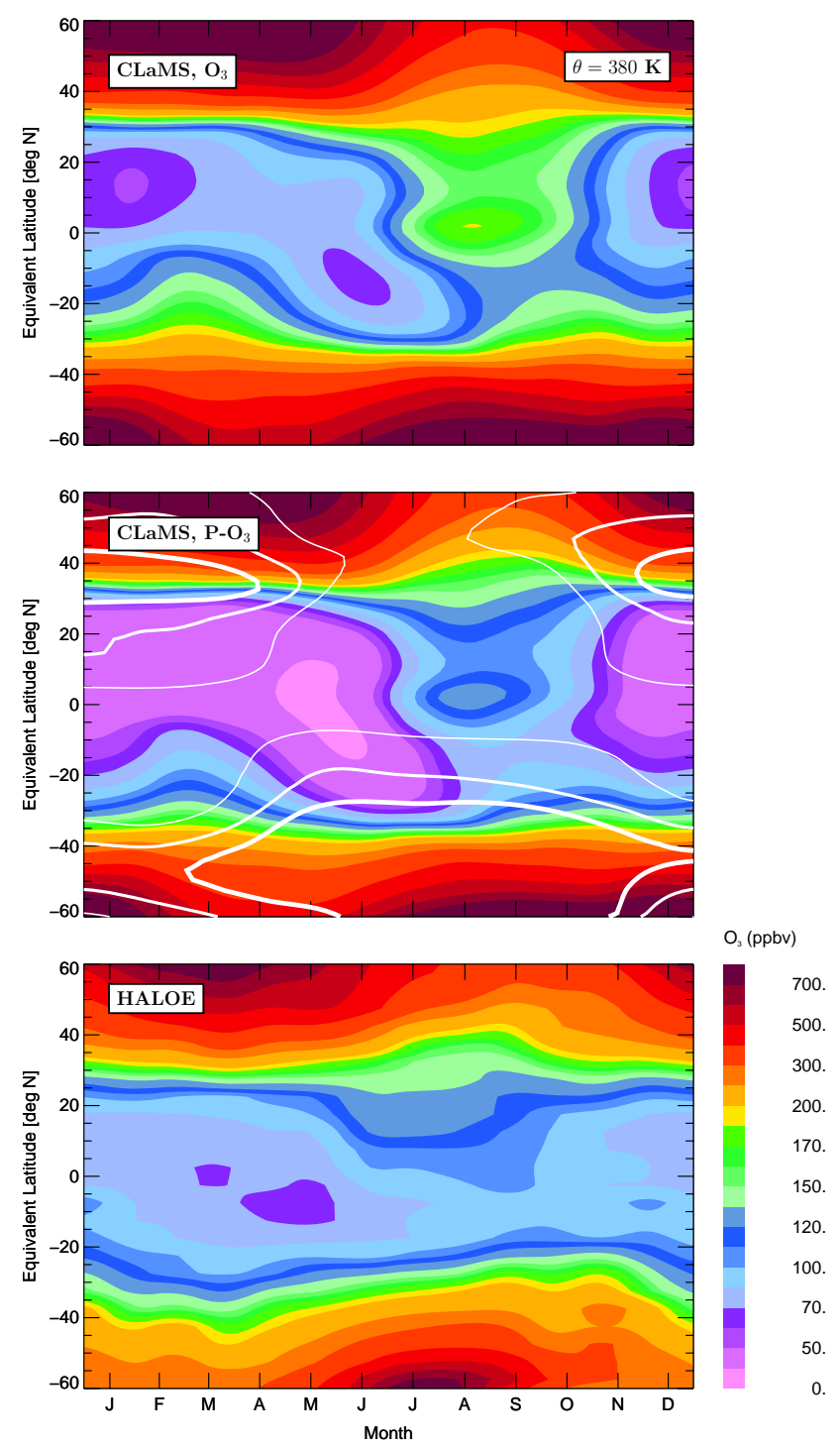

Fig. 4. The seasonality of $\mathrm{O}_{3}$ (top), $\mathrm{P}-\mathrm{O}_{3}$ (passively transported $\mathrm{O}_{3}$, middle) from CLaMS (2002-2005) and from the 10-year HALOE climatology (Grooß and Russell, 2005) (bottom). The white lines are isolines of the horizontal wind plotted for 20,15 and $10 \mathrm{~m} / \mathrm{s}$ (from thick to thin).

The difference between the $\mathrm{O}_{3}$ and $\mathrm{P}-\mathrm{O}_{3}$ time series is a measure of the chemical $\mathrm{O}_{3}$ production and, as expected, the contribution of the photolytically formed $\mathrm{O}_{3}$ grows with increasing altitude. The shape of the seasonality derived from CLaMS shows a clear maximum in late summer that can also be diagnosed from the HALOE and SHADOZ observations. Furthermore, the fractional annual amplitude, $\Delta \mathrm{O}_{3} /\left\langle\mathrm{O}_{3}\right\rangle$, derived from CLaMS, decreases above $\theta=380 \mathrm{~K}$ with increasing altitude in agreement with the SHADOZ observations shown in Fig. 2, although CLaMS absolute values are considerably higher than the observations and there is a phase shift between CLaMS and $\mathrm{SHADOZ} \mathrm{O}_{3}$ maximum that also increases with altitude (top panel of Fig. 5).
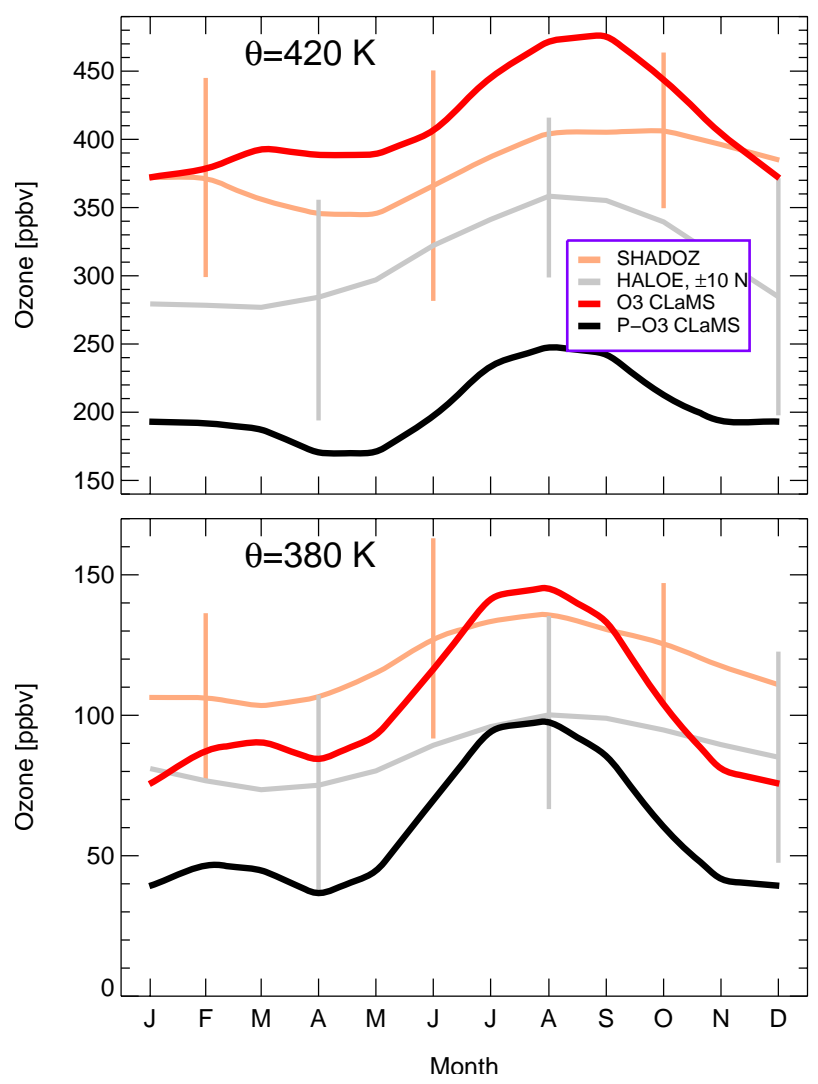

Fig. 5. Seasonality of the SHADOZ observations (seven closest stations to the equator, beige) versus CLaMS time series of $\mathrm{O}_{3}$ and $\mathrm{P}_{-} \mathrm{O}_{3}$ (red and black) at $\theta=380$ (bottom) and $420 \mathrm{~K}$ (top). In the case of the SHADOZ data, the beige vertical lines describe the total variability between the seven stations considered. In addition, $\mathrm{O}_{3}$ from the HALOE climatology (Grooß and Russell, 2005) averaged within the latitude range $\pm 10^{\circ} \mathrm{N}$ with corresponding standard deviation (vertical lines) is shown (gray).

A remarkable feature of the CLaMS time series is that $\mathrm{O}_{3}$ and $\mathrm{P}_{-} \mathrm{O}_{3}$ show exactly the same seasonality with a pronounced maximum in summer and a weaker second maximum around February. Moreover, the percentage of $\mathrm{P}_{-} \mathrm{O}_{3}$ at $\theta=380 \mathrm{~K}$ compared with the total simulated $\mathrm{O}_{3}$ is larger than $50 \%$, in particular in summer, indicating that, at least in the model, transport rather than chemical production determines not only the seasonality of the $\mathrm{O}_{3}$ cycle but also a significant fraction of the ozone budget. Thus, although CLaMS overestimates the semi-annual cycle of $\mathrm{O}_{3}$, the model results reproduce the observed seasonality.

A strong station-to-station variability of the SHADOZ data, in particular below $360 \mathrm{~K}$, is much higher than the corresponding variability of the CLaMS time series (not shown). Here, CLaMS underestimates the variability of the convection-driven transport, at least at the location of the SHADOZ stations considered. This is plausible because below $100 \mathrm{hPa}$ CLaMS uses the large-scale ECMWF vertical winds which do not give sufficient consideration to the effect 


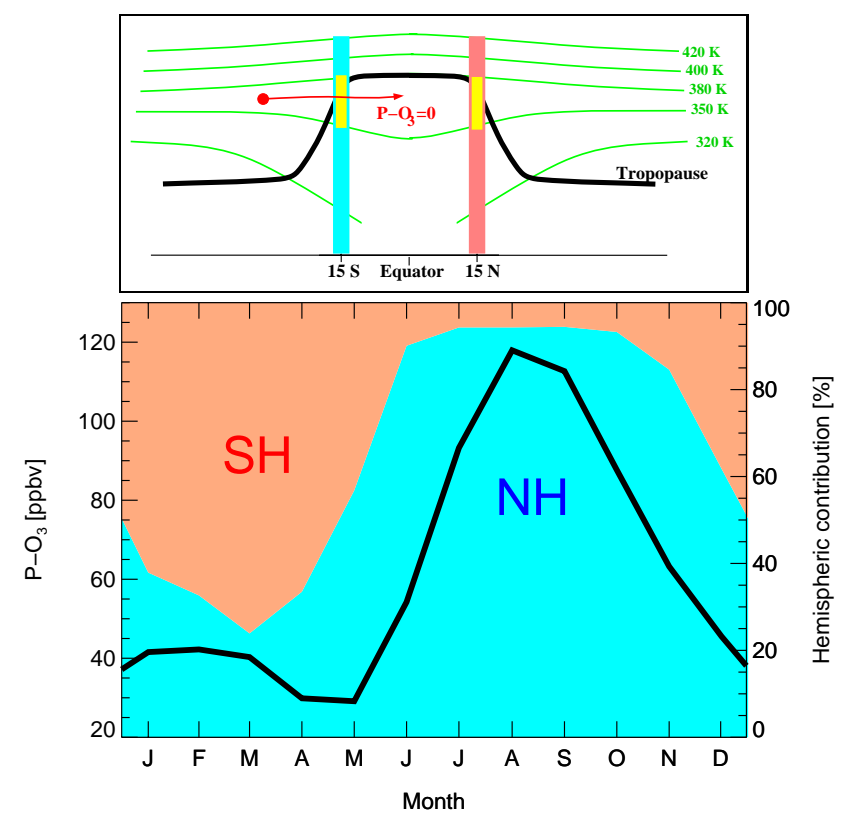

Fig. 6. Seasonality of in-mixing diagnosed from CLaMS sensitivity studies. Top: Setup with two artificial meridional transport barriers at $\pm 15^{\circ} \mathrm{N}$. Bottom: Relative contribution of the Northern $(\mathrm{NH}$, cyan) and Southern (SH, orange) Hemisphere (in \%, right axis) to the seasonality of CLaMS passive ozone $\left(\mathrm{P}-\mathrm{O}_{3}\right)$ in the tropics $\left( \pm 10^{\circ} \mathrm{N}\right)$ at $\theta=380 \mathrm{~K}$ (black line).

of the localized convection that can penetrate deeply into the stratosphere (Ricaud et al., 2007).

Finally, we discuss which transport process in the model (horizontal or vertical advection or the diffusive part of transport, i.e. mixing) is responsible for the seasonality of $\mathrm{P}_{-} \mathrm{O}_{3}$. We employ a model set-up that allows the contribution of stratospheric $\mathrm{O}_{3}$ to the $\mathrm{O}_{3}$ in the TTL to be quantified (see middle panel in Fig. 4 and the black lines in the bottom panel of Fig. 6 quantifying $\mathrm{P}^{-} \mathrm{O}_{3}$ at $\theta=380 \mathrm{~K}$ within the $\pm 10^{\circ} \mathrm{N}$ band). In particular, we trace back the origin of the air responsible for the strong annual and weak semi-annual cycle of enhanced $\mathrm{P}_{-} \mathrm{O}_{3}$ at $\theta=380 \mathrm{~K}$. For this purpose, model simulations are carried out with two artificial meridional transport barriers which are set in both hemispheres along the $\pm 15^{\circ} \mathrm{N}$ latitude and which extend vertically between the Earth's surface and the $420 \mathrm{~K}$ isentrope (thick cyan and orange lines in the top panel of Fig. 6).

CLaMS transport can be understood as a consecutive succession of pure advective (24-h trajectories) and mixing steps applied for all Lagrangian air parcels. In our sensitivity studies, we set the $\mathrm{P}_{-} \mathrm{O}_{3}$ value of each CLaMS air parcel to zero if the trajectory of this air parcel crosses equatorwards one of the two artificial transport barriers (see the idealized red trajectory in Fig. 6, crossing the cyan meridional barrier). In this way we set the advective, equatorward transport to zero, so only the diffusive transport across the barrier or the transport from above the upper edge of the barriers can influence
$\mathrm{P}_{-} \mathrm{O}_{3}$ in the tropics (note that $\mathrm{P}-\mathrm{O}_{3}$ at the Earth's surface is set to zero).

In our first model simulation, both transport barriers are active, so only the diffusive flux across the barriers and the total (i.e. advective+diffusive) flux from above $\theta=420 \mathrm{~K}$ can contribute to the tropical $\pm 10^{\circ} \mathrm{N}$ seasonality of $\mathrm{P}-\mathrm{O}_{3}$ at $\theta=380 \mathrm{~K}$. However, our simulations show that the contribution of all these fluxes is smaller than $1 \%$ and is therefore negligible. On the other side, CLaMS simulations with mixing switched off (i.e. pure trajectory transport, not shown) show the same seasonality of $\mathrm{P}_{-} \mathrm{O}_{3}$ although the absolute values of $\mathrm{P}-\mathrm{O}_{3}$ are significantly higher.

Thus, we conclude that advective transport across the barriers determines the seasonality of $\mathrm{P}_{-} \mathrm{O}_{3}$ at $\theta=380 \mathrm{~K}$ whereas the diffusive transport is responsibly for the absolute values of $\mathrm{P}_{-} \mathrm{O}_{3}$ rather than for its annual or semi-annual cycles. Note that in our idealized study with advective, equatorward transport set to zero, the corresponding diffusive transport is higher compared with the case when advection is not switched off (because $\mathrm{P}^{-} \mathrm{O}_{3}$ gradients across the barrier are larger). Thus, even when diffusive transport is artificially enhanced, its impact on the seasonality of $\mathrm{P}^{-} \mathrm{O}_{3}$ within $\pm 10^{\circ} \mathrm{N}$ range is negligible.

In the second model study, we quantify the contribution of both hemispheres to the $\pm 10^{\circ} \mathrm{N}$ seasonality of $\mathrm{P}_{-} \mathrm{O}_{3}$ at $\theta=380 \mathrm{~K}$ (black line in the bottom panel of Fig. 6). By switching on only one of the artificial transport barriers, the relative contributions (in \%) of the northern (only the cyan barrier is active) and Southern Hemisphere (only the orange barrier is active) were determined. The results are shown in the bottom panel of Fig. 6 with the right axis as the reference for the percentage and with the cyan and orange colors marking the contribution of the northern and Southern Hemisphere, respectively. Thus, more than $90 \%$ of $\mathrm{P}_{-} \mathrm{O}_{3}$ is transported from the Northern Hemisphere in summer and more than $60 \%$ of the weak maximum in February is caused by transport from the Southern Hemisphere.

In the last sensitivity study, we quantify those vertical regions of the barriers (without resolving any longitudinal dependence) through which the contribution of the advective transport to the seasonality of $\mathrm{P}_{-} \mathrm{O}_{3}$ at $\theta=380 \mathrm{~K}$ is largest. Here, a $30 \mathrm{~K}$ "window" is defined in each artificial transport barrier (yellow segments in the top panel of Fig. 6) through which the trajectories can pass. By varying the vertical position of these windows, which can be shifted between the Earth's and the $\theta=420 \mathrm{~K}$ surface, the $\theta$-range with the strongest contribution to the seasonality of $\mathrm{P}_{-} \mathrm{O}_{3}$ at $\theta=380 \mathrm{~K}$ can be found. Our simulations show that about $80 \%$ of the $\mathrm{P}^{-} \mathrm{O}_{3}$ seasonality at $380 \mathrm{~K}$ is due to transport across the windows extending between 370 and $400 \mathrm{~K}$ (that is comparable with the pure trajectory study discussed by Ploeger et al. (2009)).

Thus, although the minimum of $\mathrm{P}_{-} \mathrm{O}_{3}$ in the tropics at $\theta=380 \mathrm{~K}$ (see middle panel in Fig. 4 or bottom panel of Fig. 6) is due to seasonality of up-welling, the maximum 

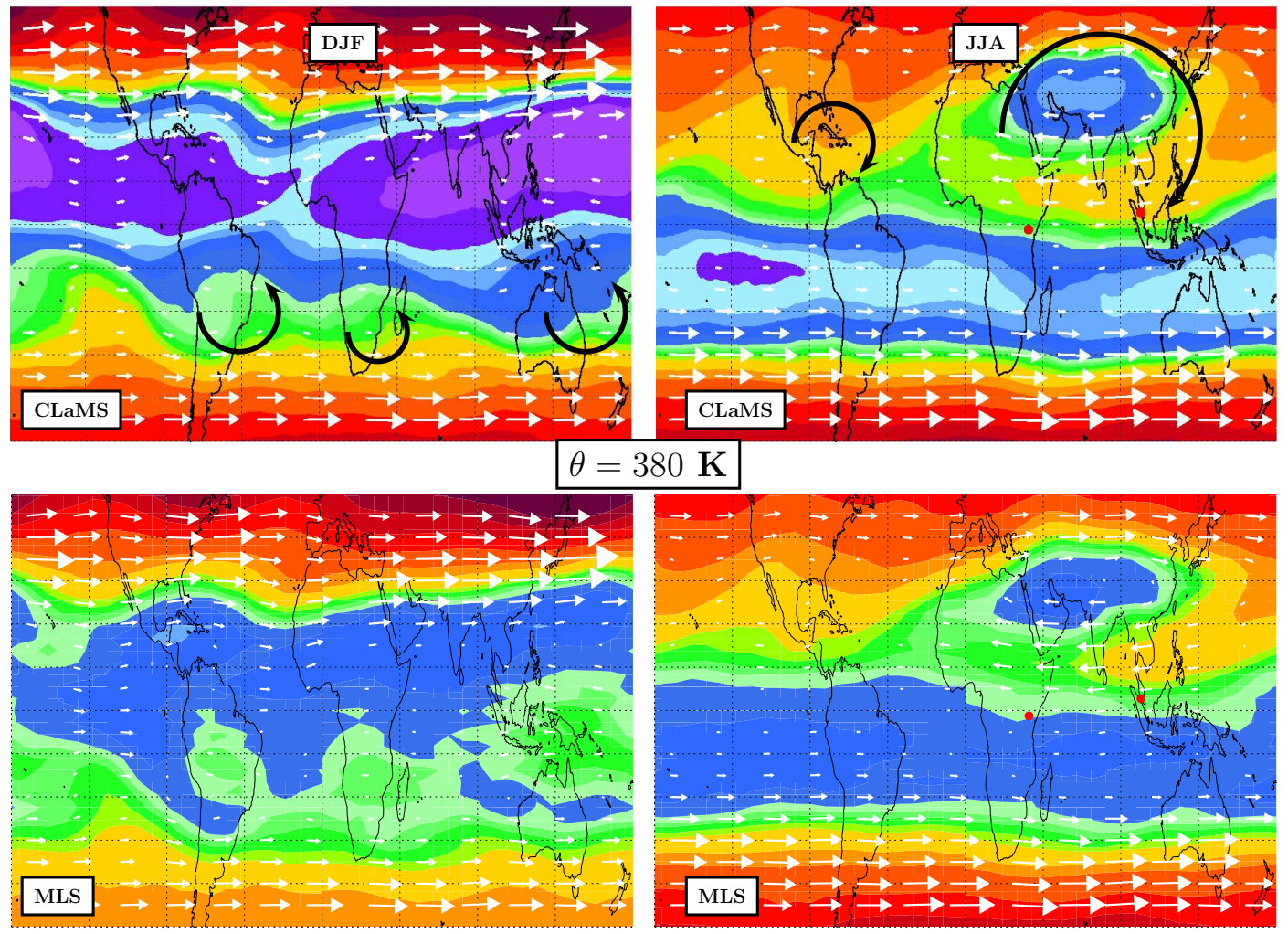

$\mathrm{O}_{3}(\mathrm{ppbv})$

700.

500.

300.

200.

170.

150.

120.

100.

70.

50.

Fig. 7. Mean distribution of $\mathrm{O}_{3}$ at $\theta=380 \mathrm{~K}$ as calculated with CLaMS (top) and derived from Aura MLS observations (bottom, Version 2.2) during the winter (DJF, left) and summer (JJA, right). For CLaMS and MLS the averaged values over the 2002-2005 and 2005-2007 periods, respectively, were calculated. The white arrows denote the isentropic wind derived from ECMWF data covering the 2002-2005 period. The black arrows denote the anticyclones in the northern (Asian and American monsoon) and in the Southern Hemisphere (Bolivian high, Australian monsoon and a weak anticyclone over South Africa), which drive in-mixing and are responsible for enhanced $\mathrm{O}_{3}$ in $\mathrm{MLS}$ observations. The thick red points are locations of the two SHADOZ stations (Kuala Lumpur and Nairobi)

of $\mathrm{P}-\mathrm{O}_{3}$ can only be understood as a consequence of inmixing with the most dominant contribution from the Northern Hemisphere in summer. On the other hand, the weaker winter maximum diagnosed in the model is hardly present in the HALOE/SHADOZ observations. In CLaMS this signal is caused by enhanced equatorward transport from the Southern Hemisphere into the tropics during austral summer.

\section{In-mixing and the Asian monsoon anticyclone}

The importance of in-mixing for the composition of air around the tropical tropopause can also be deduced from the structure of the zonal winds shown in the middle panel of Fig. 4 (white lines are plotted for 20,15 and $10 \mathrm{~m} / \mathrm{s}$, from thick to thin line, respectively). Here, a difference between the Northern and Southern Hemisphere is obvious. In both hemispheres the subtropical jet is weaker during the respective summer season than during the respective winter season (Chen, 1995) with the smallest zonal winds in the Northern Hemisphere in summer. The subtropical jet in the Southern
Hemisphere forms an effective transport barrier during the whole year even if some weaker signatures of in-mixing from the Southern Hemisphere can be seen during the austral summer (see enhanced $\mathrm{P}_{-} \mathrm{O}_{3}$ in February, March at $20^{\circ} \mathrm{S}$ ).

The most pronounced hemispheric asymmetry of the climatological flow pattern in the vicinity of the tropopause originates from the Asian summer monsoon that manifests as a strong anticyclone in the upper troposphere (Dethof et al., 1999; Randel and Park, 2006; Park et al., 2007). This nearly stationary summer circulation extends well into the lower stratosphere up to about $20 \mathrm{~km}$ (or $\theta=420 \mathrm{~K}$ ) and effectively isolates the air masses of tropospheric origin inside from much older, mainly stratospheric air outside this anticyclone (Park et al., 2008). Furthermore, this circulation significantly weakens the subtropical jet making it permeable for meridional transport (Haynes and Shuckburgh, 2000).

In Fig. 7 the horizontal distribution of $\mathrm{O}_{3}$ at $\theta=380 \mathrm{~K}$ is shown for the winter months, December to February (DJF, left) and summer months, June to August (JJA, right) derived from the CLaMS simulations (2002-2005, top) and observations measured by the Microwave Limb Sounder (MLS) on 
the NASA Earth Observing System (EOS) Aura (Schoeberl et al., 2006) (bottom). The MLS profiles (Version 2.2) sampled between August 2004 and December 2008 were first interpolated on the model $\theta$-levels (using ECMWF temperature) and then both CLaMS data and MLS observations were averaged within $250 \times 250 \mathrm{~km}$ bins. The precision and the uncertainty of MLS data amounts to 40 and $50 \mathrm{ppbv}$ at $100 \mathrm{hPa}$, respectively (Livesey et al., 2008).

To mimic the $4 \mathrm{~km}$ vertical resolution and the averaging kernel of the MLS retrieval procedure, the CLaMS data are averaged over three isentropic levels, 370, 380, and $400 \mathrm{~K}$. The comparison between the CLaMS and the MLS data shows that although very similar patterns are resolved by both data sets, the $\mathrm{O}_{3}$ mixing ratios measured by MLS are higher than the corresponding CLaMS values (with the exception of the Southern Hemisphere in DJF where CLaMS overestimates MLS mainly due to missing the halogeninduced $\mathrm{O}_{3}$ loss forming the ozone hole and propagating downwards in austral summer). Although the absolute difference increases towards the poles, the relative difference is of the order $10 \%$ and thus in rough agreement with the relative accuracy of the MLS retrieval discussed in Livesey et al. (2008).

Nevertheless, the similarity of the patterns between MLS and CLaMS, with the lowest $\mathrm{O}_{3}$ values over the equator in winter and with a clear signature of the Asian monsoon anticyclone in summer, confirms the seasonality of transport resolved by CLaMS. In particular, the summer distribution of $\mathrm{O}_{3}$ shows a very pronounced wave- 2 structure with the highest values of $\mathrm{O}_{3}$ in the eastern flank of the Asian monsoon and over Central America. While the Asian monsoon anticyclone is also obvious in the wind pattern, it is not clear to what extent the second maximum over Central America is driven by the North American monsoon (black arrow in the top right panel of Fig. 7).

A weaker signature of in-mixing at $\theta=380 \mathrm{~K}$ can also be inferred due to the Australian or South American monsoon in winter (black arrows in the top left panel of Fig. 7). The latter is mainly driven by the quasi-stationary Bolivian high circulation that has some similarities with the Asian summer monsoon anticyclone (Zhou and Lau, 1998). It is noteworthy that the MLS data shows these signatures more clearly than CLaMS, with some indication of the anticyclonic flow over South Africa, although it is difficult to estimate the impact of the retrieval on the vertical resolution. In contrast to much weaker anticyclones on the Southern Hemisphere, the signature of the Asian monsoon can also be diagnosed at $\theta=420 \mathrm{~K}$, both in MLS and CLaMS data (not shown).

In-mixing into the TTL in the Southern Hemisphere was also deduced from the ozone profiles measured with the Systeme d'Analyse par Observation Zenithale (SOAZ) UV-vis spectrometer and flown onboard long duration balloons in the latitude range $20 \pm 5^{\circ} \mathrm{S}$. These profiles show an increased $\mathrm{O}_{3}$ variability in the TTL with a maximum at $14-15 \mathrm{~km}$ immediately below the tropopause (Borchi et al., 2005).
As in the MLS data, the impact of the Asian monsoon on the seasonality of $\mathrm{O}_{3}$ should be noticeable in the SHADOZ observations, in particular in those which are located downwind (in the climatological sense) of the Asian monsoon anticyclone (see red filled circles in Fig. 7 marking the geographical location of the Kuala Lumpur and Nairobi stations). In Fig. 8, the seasonality of $\mathrm{O}_{3}$ (green) observed at Kuala Lumpur $\left(101.7^{\circ} \mathrm{E}, 2.73^{\circ} \mathrm{N}\right)$ and Nairobi $\left(36.8^{\circ} \mathrm{E}, 1.27^{\circ} \mathrm{S}\right)$ is compared with the corresponding CLaMS time series of $\mathrm{O}_{3}$ (red) and $\mathrm{P}_{-} \mathrm{O}_{3}$ (black) for $\theta=380$ (bottom) and $420 \mathrm{~K}$ (top). The model reproduces the observed seasonality fairly well, although, both the annual cycle and the decrease of the ozone maximum with distance from the Asian monsoon are more pronounced in the model than in the observations.

Remarkable is also the temporal shift of this maximum towards autumn with increasing downwind distance, e.g. $\mathrm{O}_{3}$ maximum in Nairobi at $\theta=420 \mathrm{~K}$ is about $1-2$ months later than in Kuala Lumpur (the observed shift is slightly larger than that resulting from the model). This is consistent with the picture that if a zonally asymmetric process like the Asian monsoon is responsible for the ozone seasonal cycle, this should translate into a phase shift between the ozone maxima at different SHADOZ stations. In particular the phase shift at the tropical station slightly southern of the equator (Nairobi) is expected to be later than at the station that is more directly influenced by the Asian monsoon anticyclone (Kuala Lumpur). For typical zonal winds of the order $10 \mathrm{~m} / \mathrm{s}$, this phase shift is expected to be comparable with the time that air at the equator needs to circle around the world, i.e. $\approx 1.5$ months.

In summary, for an aqua-planet with negligible tropospheric sources of $\mathrm{O}_{3}$ one would expect that summer and winter $\mathrm{O}_{3}$ distributions are symmetric to each other. However, the real atmosphere shows an annual cycle in the tropical upwelling that is approximately anticorrelated to the wellknown seasonal variation of the tropical temperatures, i.e. the slowest and fastest upwelling occurs during the summer and winter, respectively (Randel et al., 2007). Our study shows that as a complement to to the annual cycle of upwelling, the seasonality of in-mixing, mainly in summer from the Northern Hemisphere and mainly driven by the Asian monsoon anticyclone, significantly modulates tropical $\mathrm{O}_{3}$ between 380 and $420 \mathrm{~K}$ potential temperature.

\section{Discussion}

Based on a simple conceptual model of transport and photochemistry, Konopka et al. (2009) argued that the observed seasonality of $\mathrm{O}_{3}$ with the highest values during boreal summer, cannot be understood merely by photolytical $\mathrm{O}_{3}$ production in slowly rising air masses which are well-isolated from the extratropics. Utilizing CLaMS, we have discussed the contribution of horizontal transport from the extratropics into the TTL, referred here as in-mixing, to the seasonality 

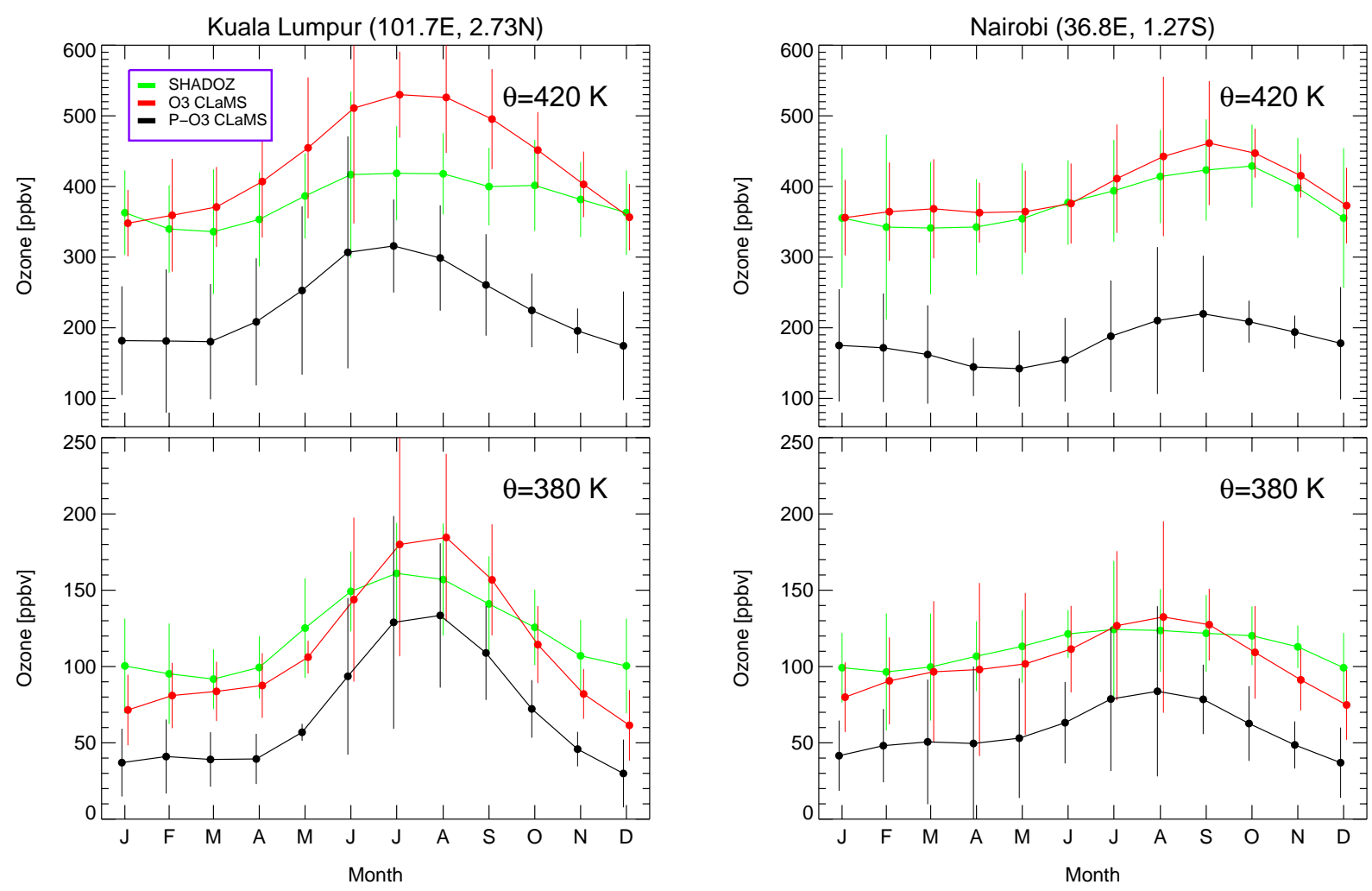

Fig. 8. Seasonality of $\mathrm{O}_{3}$ at two SHADOZ stations: Kuala Lumpur and Nairobi. Both stations are located downwind of the Asian monsoon anticyclone (see also red filled circles in Fig. 7).

of $\mathrm{O}_{3}$ in the TTL. In particular, the use of the passively transported $\mathrm{O}_{3}, \mathrm{P}_{-} \mathrm{O}_{3}$, allows the impact of horizontal transport to be quantified more precisely.

As we showed in our sensitivity studies where the advective part of transport was switched on and off, the seasonality of in-mixing (which is strongest from the Northern Hemisphere in late summer) together with the seasonality of upwelling (which is strongest in April) determines the seasonality of $\mathrm{P}_{-} \mathrm{O}_{3}$ at $\theta=380 \mathrm{~K}$. Furthermore, based on our sensitivity studies, an impact of advective and/or diffusive transport in the tropics from above $\theta=420 \mathrm{~K}$ on air masses at $\theta=380 \mathrm{~K}$ was also excluded. This is because, at least in the model, upwelling with persistent positive (upward) values of $\dot{\theta}$ determines transport above the $Q=0$ level $(\approx 360 \mathrm{~K})$. We conclude that the seasonality of in-mixing is mainly driven by meridional, isentropic winds, i.e. by advective rather than by the diffusive transport. The diffusive transport determines much more the absolute value of in-mixed air and not the annual or semi-annual cycle of in-mixing. Thus, in-mixing itself can be understood as irreversible transport in the sense that air masses which crossed the lateral boundary of the TTL equatorwards do not move back but ascend into the stratosphere with the large-scale Brewer-Dobson circulation.
A remarkable result of the CLaMS simulations is the percentage of $\mathrm{P}_{-} \mathrm{O}_{3}$ compared with the total $\mathrm{O}_{3}$ (Fig. 9) that can be used as a measure of in-mixing. More precisely, the fraction $\mathrm{P}-\mathrm{O}_{3} /\left(\mathrm{O}_{3}+\mathrm{O}_{3}\right.$ trop $)$ was derived from the model with $\mathrm{O}_{3 \text { trop }}$ estimating the maximum contribution of the troposphere to the seasonality of $\mathrm{O}_{3}$ in the TTL (in CLaMS the

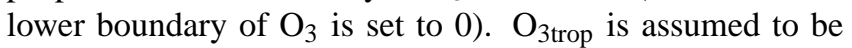
40 ppbv. With this assumption $\mathrm{O}_{3}+\mathrm{O}_{3}$ trop roughly reproduces the SHADOZ climatology at $\theta=360 \mathrm{~K}$ (not shown).

Thus, Fig. 9 clearly shows a minimum of in-mixed $\mathrm{O}_{3}$ in spring and a strong enhancement (up to 60\%) of in-mixing during late summer and early fall within the $\theta$-range between 370 and $420 \mathrm{~K}$. This seasonality of transport was also suggested by Yang et al. (2008) who found that during boreal summer the upward mass flux in the tropics has a near-zero minimum around $70 \mathrm{hPa}$ and, consequently, the mass flux below this level is decoupled from that above.

Note that CLaMS simulations with non mass-conserving vertical velocity reduce the numbers of in-mixing shown in Fig. 9 although its pattern with a pronounced maximum in summer remains unchanged. Because the corrected vertical velocity not only removes the gap in upwelling discussed in Konopka et al. (2007) but also reproduces better the $\mathrm{H}_{2} \mathrm{O}$ tape-recorder and the tropical $\mathrm{CH}_{4}$ profiles (not shown), we consider the corresponding values of in-mixed $\mathrm{O}_{3}$ shown 


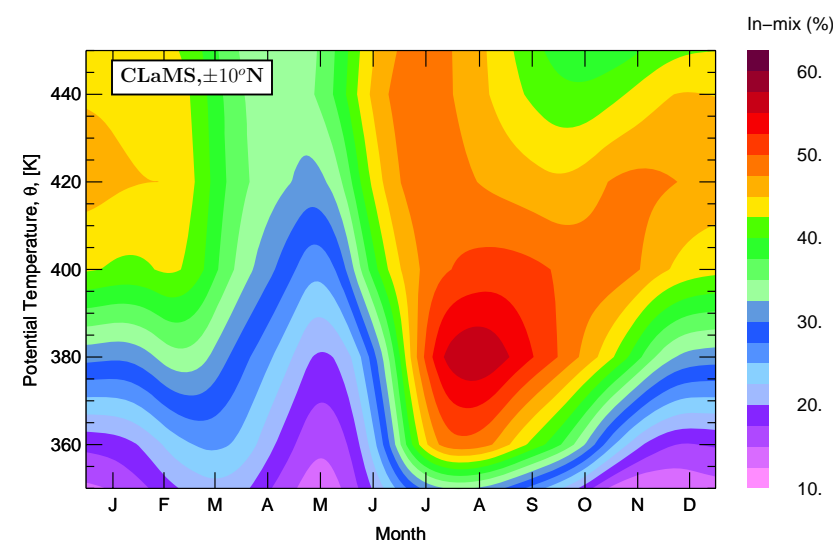

Fig. 9. Contribution of in-mixing calculated from CLaMS as a fraction of $\mathrm{P}-\mathrm{O}_{3} /\left(\mathrm{O}_{3}+\mathrm{O}_{3 \text { trop }}\right)$. $\mathrm{O}_{3 \text { trop }}$ describes the $\mathrm{O}_{3}$ flux from the troposphere that was assumed to be $40 \mathrm{ppbv}$ (in CLaMS this contribution is neglected due to the condition $\mathrm{O}_{3}=0$ at the Earth's surface)

Fig. 9 to be more reliable. Also the mixing itself that can can be switched off in CLaMS simulation has a strong impact on the numbers (but not on the seasonality) shown in Fig. 9.

The origin of enhanced in-mixing can be traced back to a strongly disturbed zonal flow on the Northern Hemisphere in summer, mainly by the persistent Asian monsoon anticyclone (wave-2 pattern, see Fig. 7), in qualitative agreement with idealized, isentropic studies of transport (Chen, 1995; Plumb, 1996; Haynes and Shuckburgh, 2000; Ploeger et al., 2009). On the other side, persistent anticyclones during the Southern Hemisphere summer (Bolivian high, or Australian monsoon) although much weaker than the Asian monsoon anticyclone, also contribute to in-mixing into the TTL (Borchi et al., 2005).

Finally, in addition to the described scenarios of the vertical velocities, sensitivity studies were carried out with CLaMS driven by the ERA-Interim meteorology with vertical wind derived from the temperature tendencies due to radiation (clear sky and clouds) and latent heat (Fueglistaler et al., 2009b; Ploeger et al., 2009). All these studies show consistently that although the absolute values of in-mixing (i.e. of $\mathrm{P}-\mathrm{O}_{3}$ ) or of the fractional annual amplitude $\Delta \mathrm{O}_{3} /\left\langle\mathrm{O}_{3}\right\rangle$ or of its phase depend on the vertical wind and on the intensity of mixing considered in the model, the presented seasonality of $\mathrm{O}_{3}$ is a very robust feature of all our simulations.

\section{Conclusions}

Multi-annual simulations with the the Chemical Model of the Stratosphere (CLaMS) suggest that in-mixing from the northern extra-tropics in summer, in particular in connection with the summer Asian monsoon, significantly influences the composition of air within the TTL between 380 and $420 \mathrm{~K}$ potential temperature. Our study also shows that the picture of a TTL, "well-isolated" from the extratropics, should be revised, in particular for altitudes between 370 and $440 \mathrm{~K}$, by a picture where both the annual cycle of upwelling and of horizontal transport determine the seasonality of $\mathrm{O}_{3}$ and of other relevant species in the TTL.

\section{Appendix A}

\section{Annually averaged mass conservation}

Although the diabatic approach for the vertical velocities allows us to define vertical transport from the diabatic heat budget, the greatest disadvantage of this procedure is the fact that the continuity equation is not fulfilled. A much weaker requirement than the rigorous validity of the continuity equation is the condition that the annually averaged total mass fluxes vanish at each $\theta$-level (Rosenlof, 1995), i.e.

$\forall \theta \quad \int_{-90}^{+90} \sigma(\lambda) \dot{\theta}(\lambda) \cos \lambda d \lambda=R=0$

where $\lambda$ is the latitude. The mass density $\sigma$ on an isentropic surface is given as $\sigma=-(1 / g) \partial p / \partial \theta$ (Andrews et al., 1987) and $\dot{\theta}$ denotes the isentropic vertical velocity. Here, the zonally and annually averaged values of $\sigma$ and $\dot{\theta}$ are used (although the averaged values of the product $\sigma \dot{\theta}$ would be more appropriate, the resulting difference is negligible)

We modify the general procedure formulated by Rosenlof (1995) and correct $\dot{\theta}$ by $\dot{\theta} \rightarrow \dot{\theta}+c f(\lambda)$ with $f(\lambda)=\cos \left(k \lambda / \lambda_{0}\right), \quad k=\pi / 2$ for $|\lambda|<\lambda_{0}$ and 0 elsewhere (here $\lambda_{0}$ was set to $50^{\circ} \mathrm{N}$ ). Inserting of the corrected vertical velocity into Eq. (A1) yields a condition for the constant $c$, i.e. $c=-R / H$ with

$H=\int_{-\lambda_{0}}^{+\lambda_{0}} \sigma(\lambda) f(\lambda) \cos \lambda d \lambda$

The weighting function $f$ can be eliminated by setting $f=1$ and $\lambda_{0}=90$. In general $c$ is different for each $\theta$ surface. In this paper, we use the constant and latitude-weighted correction above and below $\theta=360 \mathrm{~K}$, respectively.

Acknowledgements. We thank William J. Randel for many discussions motivating the authors to conduct this study and to write this paper. We are also grateful to Mijeong Park for providing us with SHADOZ-based $\mathrm{O}_{3}$-climatology. Work at the Jet Propulsion Laboratory, California Institute of Technology, was carried out under a contract with the National Aeronautics and Space Administration. The European Centre for Medium-Range Weather Forecasts (ECMWF) provided meteorological analyses for this study. Excellent programming support was provided by $\mathrm{N}$. Thomas. Comments by two anonymous reviewers led to substantial improvements of this paper.

Edited by: M. Dameris 


\section{References}

Andrews, D. G., Holton, J. R., and Leovy, C. B.: Middle Atmosphere Dynamics, Academic Press, San Diego, USA, 1987.

Avallone, L. M. and Prather, M. J.: Tracer-tracer correlations: Three-dimensional model simulations and comparisons to observations, J. Geophys. Res., 102, 19233-19246, 1997.

Borchi, F., Pommereau, J.-P., Garnier, A., and Pinharanda, M.: Evaluation of SHADOZ sondes, HALOE and SAGE II ozone profiles at the tropics from SAOZ UV-Vis remote measurements onboard long duration balloons, Atmos. Chem. Phys., 5, 13811397, 2005,

http://www.atmos-chem-phys.net/5/1381/2005/.

Chae, J. H. and Sherwood, S. C.: Annual temperature cycle of the tropical tropopause: A simple model study, J. Geophys. Res., 112, 1-10, 2007.

Chen, P.: Isentropic cross-tropopause mass exchange in the extratropics, J. Geophys. Res., 100, 16661-16673, 1995.

Dethof, A., O'Neill, A., Slingo, J. M., and Smit, H. G. J.: A mechanism for moistening the lower stratosphere involving the Asian summer monsoon, Q. J. Roy. Meteorol. Soc., 556(125), 10791106, 1999.

Folkins, I., Loewenstein, M., Podolske, J., Oltmans, S. J., and Proffitt, M.: A barrier to vertical mixing at $14 \mathrm{~km}$ in the tropics: Evidence from ozonesondes and aircraft measurements, Geophys. Res. Lett., 104, 22095-22102, 1999.

Folkins, I., Bernath, P., Boone, C., Lesins, G., Livesey, N., Thompson, A. M., Walter, K., and Witte, J. C.: Seasonal cycles of $\mathrm{O}_{3}$, $\mathrm{CO}$, and convective outflow at the tropical tropopause, Geophys. Res. Lett., 33, L16802, doi:10.1029/2006GL026602, 2006.

Fueglistaler, S., Dessler, A. E., Dunkerton, T. J., Folkins, I., Fu, Q., and Motte, P. W.: Tropical tropopause layer, Rev. Geophys., 47, RG1004, doi:10.1029/2008RG000267, 2009a.

Fueglistaler, S., Legras, B., Beljaars, A., Morcrette, J.-J., Simmons, A., Tompkins, A. M., and Uppapla, S.: The diabatic heat budget of the upper troposphere and lower/mid stratosphere in ECMWF reanalysis, Q. J. Roy. Meteorol. Soc., 135, 21-37, doi:10.1002/ qj.361, 2009b.

Gettelman, A., de F. Fujiwara, P. M., Fu, Q., Vömel, H., Gohar, L. K., Johanson, C., and Aaammerman, M.: Radiation balance of the tropical tropopause layer, J. Geophys. Res., 109, D07103, doi:10.1029/2003JD004190, 2004.

Grooß, J.-U.: Modelling of Stratospheric Chemistry based on HALOE/UARS Satellite Data, PhD thesis, University of Mainz, 1996.

Grooß, J.-U. and Russell III, J. M.: Technical note: A stratospheric climatology for $\mathrm{O}_{3}, \mathrm{H}_{2} \mathrm{O}, \mathrm{CH}_{4}, \mathrm{NO}_{\mathrm{x}}, \mathrm{HCl}$ and $\mathrm{HF}$ derived from HALOE measurements, Atmos. Chem. Phys., 5, 2797-2807, 2005 ,

http://www.atmos-chem-phys.net/5/2797/2005/.

Haynes, P. and Shuckburgh, E.: Effective diffusivity as a diagnostic of atmospheric transport, 2, Troposphere and lower stratosphere, J. Geophys. Res., 105, 22795-22810, 2000.

Konopka, P., Günther, G., Müller, R., dos Santos, F. H. S., Schiller, C., Ravegnani, F., Ulanovsky, A., Schlager, H., Volk, C. M., Viciani, S., Pan, L. L., McKenna, D.-S., and Riese, M.: Contribution of mixing to upward transport across the tropical tropopause layer (TTL), Atmos. Chem. Phys., 7, 3285-3308, 2007, http://www.atmos-chem-phys.net/7/3285/2007/.

Konopka, P., Grooß, J.-U., Plöger, F., and Müller, R.: Annual cycle of horizontal in-mixing into the lower tropical stratosphere, J. Geophys. Res., 114, D19111, doi:10.1029/2009JD011955, 2009.

Krger, K., Tegtmeier, S., and Rex, M.: Variability of residence time in the Tropical Tropopause Layer during Northern Hemisphere winter, Atmos. Chem. Phys., 9, 6717-6725, 2009,

http://www.atmos-chem-phys.net/9/6717/2009/.

Livesey, N. J., Filipiak, M. J., Froidevaux, L., Read, W. G., Lambert, A., Santee, M. L., Jiang, J. H., Pumphrey, H. C., Waters, J. W., Cofield, R. E., Cuddy, D. T., Daffer, W. H., Drouin, B. J., Fuller, R. A., Jarnot, R. F., Jiang, Y. B., Knosp, B. W., Li, Q. B., Perun, V. S., Schwartz, M. J., Snyder, W. V., Stek, P. C., Thurstans, R. P., Wagner, P. A., Avery, M., Browell, E. V., Cammas, J.-P., Christensen, L. E., Diskin, G. S., Gao, R.-S., Jost, H.-J., Loewenstein, M., Lopez, J. D., Nedelec, P., Osterman, G. B., Sachse, G. W., and Webster, C. R.: Validation of Aura Microwave Limb Sounder $\mathrm{O}_{3}$ and $\mathrm{CO}$ observations in the upper troposphere and lower stratosphere, J. Geophys. Res., 113, D15S02, doi:10.1029/2007JD008805, 2008.

Mahowald, N. M., Plumb, R. A., Rasch, P. J., del Corral, J., and Sassi, F.: Stratospheric transport in a three-dimensional isentropic coordinate model, J. Geophys. Res., 107(D15), 4254, doi: 10.1029/2001JD001313, 2002.

Marcy, T. P., Popp, P. J., Gao, R. S., Fahey, D. W., Ray, E. A., Richard, E. C., Thompson, T. L., Atlas, E. L., Loewenstein, M., Wofsy, S. C., Park, S., Weinstock, E. M., Swart, W. H., and Mahoney, M. J.: Measurements of trace gases in the tropical tropopause layer, Atmos. Environ., 41, 7253-7261, 2007.

McKenna, D. S., Konopka, P., Grooß, J.-U., Günther, G., Müller, R., Spang, R., Offermann, D., and Orsolini, Y.: A new Chemical Lagrangian Model of the Stratosphere (CLaMS): 1. Formulation of advection and mixing, J. Geophys. Res., 107(D16), 4309, doi: 10.1029/2000JD000114, 2002.

Morcrette, J.-J.: Radiation and Cloud Radiative Properties in the European Centre for Medium-Range Weather Forecasts Forecasting System, J. Geophys. Res., 96(D5), 9121-9132, 1991.

Mote, P. W., Dunkerton, T. J., McIntyre, M. E., Ray, E. A., Haynes, P. H., and Russell III, J. M.: Vertical velocity, vertical diffusion, and dilution by midlatitude air in the tropical lower stratosphere, J. Geophys. Res., 103, 8651-8666, 1998.

Niwano, M., Yamazaki, K., and Shiotani, M.: Seasonal and QBO variations of ascent rate in the tropical lower stratosphere as inferred from UARS HALOE trace gas data, J. Geophys. Res., 108(D24), 4794, doi:10.1029/2003JD003871, 2003.

Park, M., Randel, W. J., Emmons, L. K., Bernath, P. F., Walker, K. A., and Boone, C. D.: Chemical isolation in the Asian monsoon anticyclone observed in Atmospheric Chemistry Experiment (ACE-FTS) data, J. Geophys. Res., 112, D16309, doi: 10.1029/2006JD008294, 2007.

Park, M., Randel, W. J., Emmons, L. K., Bernath, P. F., Walker, K. A., and Boone, C. D.: Chemical isolation in the Asian monsoon anticyclone observed in Atmospheric Chemistry Experiment (ACE-FTS) data, Atmos. Chem. Phys., 8, 757-764, 2008, http://www.atmos-chem-phys.net/8/757/2008/.

Ploeger, F., Konopka, P., Günther, G., Grooß, J.-U., and Müller, R.: Impact of the vertical velocity scheme on modeling transport across the tropical tropopause layer, J. Geophys. Res., doi:10. 1029/2009JD012023, in press, 2009.

Plumb, R. A.: A "tropical pipe" model of stratospheric transport, J. Geophys. Res., 101, 3957-3972, 1996. 
Randel, W. J. and Park, M.: Deep convective influence on the Asian summer monsoon anticyclone and associated tracer variability observed with Atmospheric Infrared Sounder (AIRS), J. Geophys. Res., 111, D12314, doi:10.1029/2005JD006490, 2006.

Randel, W. J., Park, M., Wu, F., and Livesey, N.: A large annual cycle in ozone above the tropical tropopause linked to the BrewerDobson circulation, J. Atmos. Sci., 64, 4479-4488, 2007.

Read, W. G., Schwartz, M. J., Lambert, A., Su, H., Livesey, N. J., Daffer, W. H., and Boone, C. D.: The roles of convection, extratropical mixing, and in-situ freeze-drying in the Tropical Tropopause Layer, Atmos. Chem. Phys., 8, 6051-6067, 2008, http://www.atmos-chem-phys.net/8/6051/2008/.

Ricaud, P., Barret, B., Attié, J.-L., Motte, E., Le Flochmoën, E., Teyssèdre, H., Peuch, V.-H., Livesey, N., Lambert, A., and Pommereau, J.-P.: Impact of land convection on tropospherestratosphere exchange in the tropics, Atmos. Chem. Phys., 7, 5639-5657, 2007, http://www.atmos-chem-phys.net/7/5639/2007/.

Rosenlof, K. H.: Seasonal cycle of the residual mean meridional circulation in the stratosphere, J. Geophys. Res., 100, 5173-5191, 1995.

Schoeberl, M. R., Kawa, S. R., Douglass, A. R., Waters, J., Livesey, N., Read, W., and Filipiak, M.: The carbon monoxide tape recorder, Geophys. Res. Lett., 33, L12811, doi:10.1029/ 2006GL026178, 2006.

Schoeberl, M. R., Douglass, A. R., Newman, P. A., Lait, L. R., Lary, D., Waters, J., Livesey, N., Froidevaux, L., Lambert, A., Read, W., Filipiak, M. J., and Pumphrey, H. C.: QBO and annual cycle variations in tropical lower stratosphere trace gases from HALOE and Aura MLS observations, J. Geophys. Res., 113, D05301, doi:10.1029/2007JD008678, 2008.
Thompson, A. M., Witte, J. C., Smit, H. G. J., Oltmans, S. J., Johnson, B. J., Kirchhoff, V. W., and Schmidlin, F. J.: Southern Hemisphere Additional Ozonesondes (SHADOZ) 1998-2004 tropical ozone climatology: 3. Instrumentation, station-to-station variability, and evaluation with simulated flight profiles, J. Geophys. Res., 112, D03304, 1297-1300, doi:10.1029/2005JD007042, 2007.

Tuck, A. F., Baumgardner, D., Chan, K. R., Dye, J. E., Elkins, J. W., Hovde, S. J., Kelly, K. K., Loewenstein, M., Margitan, J. J., May, R. D., Podolske, J. R., Proffitt, M. H., Rosenlof, K. H., Smith, W. L., Webster, C. R., and Wilson, J. C.: The Brewer-Dobson circulation in the light of high altitude in situ aircraft observation, Q. J. Roy. Meteorol. Soc., 123, 1-69, 1997.

Volk, C. M., Elkins, J. W., Fahey, D. W., Salawitch, R. J., Dutton, G. S., Gilligan, J. M., Proffitt, M. H., Loewenstein, M., Podolske, J. R., Minschwaner, K., Margitan, J. J., and Chan, K. R.: Quantifying transport between the tropical and mid-latitude lower stratosphere, Science, 272, 1763-1768, 1996.

Yang, Q., Fu, Q., Austin, J., Gettelman, A., Li, F., and Vömel, H.: Observationally derived and general circulation model simulated tropical stratospheric upward mass fluxes, J. Geophys. Res., 113, D00B07, doi:10.1029/2008JD009945, 2008.

Zhou, J. and Lau, K. M.: Does a Monsoon Climate Exist over South America?, J. Climate, 11, 1020-1040, 1998. 